\title{
A Pilot Study for Estimation of Environmental Losses of Pastoral Area Within Mineral Exploitation: A Case Study in Urat Rear Banner, Inner Mongolia, China*
}

\author{
Qun Zhang \\ Inner Mongolia University, Hohhot, China
}

\begin{abstract}
In grassland areas subject to pollution caused by mining, such as the Urat Rear Banner in Inner Mongolia, a reasonable compensation scenario for local herders should be considered. Willingness to pay (WTP) was assessed with the use of Contingent Valuation (CV) methodology to estimate the value for environmental losses. The results indicated that: (1) The local environmental problem included water pollution, dust, vegetation degradation, and waste pollution; (2) $65.79 \%$ of herders were not satisfied with the compensation and $56.41 \%$ of herders disagreed mining in grassland; and (3) the WTP has been estimated at 641.18 yuan annually per household. The total WTP in the mining area of Urat Rear Banner was estimated to $15,771,104.5$ yuan annually with interval estimates of $8,036,331.84$ yuan and 25,918,104.9 yuan.
\end{abstract}

Keywords: mineral exploitation, Contingent Valuation, ecological compensation, grassland pollution

\section{Introduction}

The total area of grassland in Inner Mongolia Autonomous Region (IM) is about $870,000 \mathrm{~km}^{2}$, accounting for half the total land area of the whole region. The grassland extends more than 1,000 kilometers, spanning across three climatic regions: the temperate sub-humid, semi-arid, and arid region. It is not only the base of animal husbandry and an important ecological barrier, but also rich in mineral resource (Da \& Zheng, 2006, p. 438). Up to 2017, there have been 145 kinds of minerals discovered in IM, accounting for $84.3 \%$ of all kinds of minerals that have been discovered in China. The mineral resources are distributed throughout all cities in IM. From the 21st century onward, with the economic development and the implementation of the western development strategy in China, mining in grassland has become a common practice in IM. With rich mineral resources, Inner Mongolia has gradually developed a number of pillar industries of energy, non-ferrous metals, rare earth, and others, which have laid a solid foundation for the development of modern mining industry in IM, and have made great contribution to the national and regional economic development. From 2000, mining industry has become the major industry in IM. Its profit has increased from about 0.16 billion in 2000 to 70.423 billion in 2014 with its ratio for the total industry has increased from $9.94 \%$ to $54.20 \%$ (Zhang, 2016a, pp. 59-66). However, the externality of mineral exploitation has not only exerted the negative

\footnotetext{
${ }^{*}$ Acknowledgements: This work is supported by the National Social Science Foundation of China under Grant No. 15XSH010, and the project: China Northern Minority Areas Social Survey Databases. The author would like to thank entire project team for their commitment.

Qun Zhang, Ph.D., associate professor, Department of Ethnology and Sociology, Inner Mongolia University, Hohhot, China.
} 
influence on the well-being and development of pastoralists (Wang, 2010, p. 4), but also increased the risks that pastoralists will have to endure in the future (Daia \& Ulgiatib, 2014, pp. 146-153). In addition, mineral exploration made the environment destroyed, and especially made great harm on the grassland and reduced the number of livestock. For those who rely on livestock, reducing numbers result in reduced development opportunities, and may affect social and cultural status (Carson, Flores, \& Meade, 2001, pp. 173-210). The herdsmen get very little directly benefits by receiving the compensation and donation from exploration companies. In the long run, they have to bear the ecological cost and social cost which makes them "overall loss" (Zhang, 2016b, pp. 836-843). Even worse, the gap between the rich and the poor would be consequently out of control, and contradiction among different ethnic groups would be intensified progressively (Da \& Yu, 2015, pp. 84-93). Therefore, a reasonable compensation scenario for herders must be considered in mining area. However, this proves difficult for policy makers and administrators, partly due to lack of the amount of ecological environment loss within mineral exploitation. The general objective of this study was to evaluate the utilization of Contingent Valuation (CV) as a method for assessing the willingness of local herdsmen to contribute to public good provision with focus on grassland protection within mineral exploitation, and look forward to solving the contradiction between environmental protection and mining development in Inner Mongolia grassland. The study also can be used as a quantitative basis for internalizing the external cost of environment by taxation.

\section{Methods}

\section{Study Area}

This survey was carried out in Urat Rear Banner ${ }^{1}$ (URB), which lies on the northwest of IM, ranging from east longitudes of $105^{\circ} 14^{\prime}$ to $107^{\circ} 36^{\prime}$, and north latitudes of $40^{\circ} 40^{\prime}$ to $42^{\circ} 33^{\prime}$ with a total area of 25,276 square kilometers. The altitude ranges from $1,500 \mathrm{~m}$ to $2,365 \mathrm{~m}$ with an annual average temperature of $3.8{ }^{\circ} \mathrm{C}$ (ranging from $-34.6{ }^{\circ} \mathrm{C}$ in January to $35.2{ }^{\circ} \mathrm{C}$ in July), and 130 frost days annually. The average annual rainfall generally ranges between $96 \mathrm{~mm}$ and $105.9 \mathrm{~mm}$. Most of the rainfall occurs in July and August. The grassland ecosystem is about 2,422,820 ha located in URB. The grassland area provides both local resources (forage for animals; a place to live) and acts as a natural ecological buffer and water conservation. The grassland types include mountain steppe (10.6\%), hilly steppe (61.0\%), and desert steppe (28.4\%).

There are various abundant mineral resources in URB: lead metal with a content 1,200 million tons of zinc metal, 500 million tons of copper, nearly 1.4 million tons of iron ore, nearly 30 million tons of sulfur, 7,731 tons of nickel, and 50 million tons of molybdenum (Urat Rear Banner Local Chronicles Compilation Committee, 2005 , p. 11). Although beginning at the end of 1960 s, the mining industry did not have too much effect on the local economy for a long period. In the late 1990s, URB grasped the opportunities that the national developmental strategy transferred from east to west, building a large scale of industry projects with metal as the center. An increasing number of mining factories are being built in grasslands to generate revenues through large scale mineral exploitation. Mineral exploitation is the main force of the GDP growth in URB. Based on government figures (data from Statistical Yearbook of URB 2018), there were 58 mining factories, which produced 4.92 billion yuan GDP, which accounting for $72.57 \%$ of total GDP. The per capita GDP of URB

\footnotetext{
${ }^{1}$ In the administrative organization of the Inner Mongolia Autonomous Region, banner, sum, and gachaa correspond to county, township, and village in the provinces.
} 
amounts to 15,117 dollars and reached the level of per capita GDP of a developed country. URB has become an important mineral town in IM.

URB contains two sums, three towns, and 51 gachaas. UP to 2018 , it has 65,000 people, 20 percent of which is Mongolians. Historically, herds in URB have been engaged in animal husbandry and are referred to as "the nationality on horseback". Due to serious desertification and the scattered distribution of vegetation, local herds still keep the tradition of the nomadic grazing and tame the five major kinds of the livestock, including horse, cattle, camel, sheep, and goat. By the end of 2018, there are a total of 394 thousand animal numbers in URB, including 10,000 cattle, 25,000 camels, 355,000 goats, and others. It is also worth noting that Erlangshan white goat, which grows the finest cashmere in China, is a local breed by long term selection at the specific area and environment. In recent years, mineral exploitation directly affected herdsmen's livelihood through occupying their pastures and indirectly by decreasing grassland ecosystem functions. The livelihoods of many local herds are threatened by mining.

\section{Method: Contingent Valuation}

Ecological compensation can be regarded as the price paid for individuals or regions to sacrifice their development opportunities in order to protect ecology and the environment (Liu, Wan, Zhang, \& Cai, 2008, pp. 84-93). Since Davis (1963) put forward the Contingent Valuation Method (CVM), it has been a popular and flexible non-market valuation method for ecological compensation. Despite its numerous psychological, philosophical, and technical challenges, Contingent Valuation Methods have been widely used to measure values associated with public and non-market goods (Ready, Buzby, \& Hu, 1996, pp. 397-411). With CVM, a contingent scenario is constructed and then direct money measures for the changes in welfare are elicited. CV involves the direct elicitation of respondents' willingness to pay (WTP) or willingness to accept (WTA) payment for changes in the quantity or quality of a public good or service (Fried, Adams, \& Bergland, 1995, pp. 680-686). In economics, willingness to accept (WTA) is the minimum amount of money that a person is willing to accept to abandon a good or to put up with something negative, such as pollution. It is equivalent to the minimum monetary amount required for sale of a good or acquisition of something undesirable to be accepted by an individual. Willingness to pay (WTP) is the maximum amount that people would be willing to pay for the resource or to avoid any damages that might be sustained by the resource. Economists have been using the method for well over three decades in many countries. In China, this method has been widely used in the study of natural and environmental resources' value, ecological value, social value, and people's willingness (Cao, Holden, \& Song, 2012, pp. 533-537; Qu \& Li, 2012, pp. 73-80; Lu, Chen, \& Zhu, 2018, pp. 208-214). However, there is lack of comprehensive analysis about the CVM on mining in grassland.

In many empirical CV studies, large difference between WTP and WTA has been demonstrated. WTA is usually substantially higher than WTP (Horowitz \& McConnell, 2002, pp. 426-447). An enormous literature documents that WTP is less than WTA a monetary amount for an object, a phenomenon called the endowment effect (Chapman, Ortoleva, \& Snowberg, 2017, p. 21). Some China's empirical studies indicate that WTP is better than WTA because the Chinese respondents tend to make the WTA higher than reality (Li, 2014, p. 256). In pastoral areas of URB, we opt to use WTP method. Firstly, in the long-term social practice, local herdsmen thought that they could not easily be compensated for the destruction of the ecological environment. Secondly, many herdsmen lack trust in the government. They think that even if there are compensation, it will be withheld or misappropriated by the government. It is impossible to give them the full amount. Thirdly, from the cultural 
perspective of morphology, Mongolian mode of production, value orientation, and cognitive system are the important carrier of the traditional culture (Gegengaowa, 2004, p. 192). Hence, most of Mongolian herdsmen think it should be their duty to protect the grassland under cultural influence of Mongolian.

\section{Questionnaire Design and Field Study}

The types of questionnaires on CVM include Iterative Bidding Game, Open-Ended, Payment Card, and Dichotomous Choice (DC). According to the local current situation of ecological environment and the basic principle of CVM, we applied the Payment Card (PC) to estimate the WTA of local herdsmen. The advantages of the PC approach are obvious: First, respondents' WTP values can be determined directly from the original data; second, PC respondents tend to state WTP values they are confident about (Ready, Navrud, \& Dubourg, 2001, pp. 315-326); third, WTP values estimated by a PC approach are more robust than those relying on a DC approach (Ready et al., 2001, pp. 315-326); and fourth, there is no starting point bias affecting the PC approach (Mitchell \& Carson, 1993, p. 142).

The questionnaire structure is designed to three parts in this study. The first part of the questionnaire is about the basic family situation of herds (population structure, household situation). The second part is about the understanding of grassland ecological environment and herd's attitude toward mining in grassland. The third part is the WTP question, which format used for the payment was direct payment through a "payment card", as it is assumed that this allows the user to behave as they would in a context where a product is sold at different prices (Shiell \& McIntosh, 2008, pp. 287-292). With the use of PC, respondents are given a range of values to select from bids. Respondents were given the WTP scenario and asked if they were willing to pay a certain predetermined amount (bid), i.e., a discrete yes/no bid. Respondents selected payment bids ranging from 1,000 yuan, 500 yuan, and 100 yuan from which they had to select a bid that indicates their willingness to pay for annually.

Between July and August 2019, 16 undergraduate students from the School of Ethnology and Sociology of Inner Mongolia University conducted one field questionnaires on the mining grassland of URB. We had investigated five gachaas of Sarula, Biqier, Ublig, Bayinula, and Mandula irrespectively. The selection of the gachaas was based on their proximity to the mining enterprises. The survey was deployed to a sample of 150 families selected with the use of randomized cluster sampling. At least 30 households were chosen from each gachaa. We should also note here that the households selected were particular areas that experienced the most direct impact of mineral exploitation. A total of 150 households were surveyed by face-to-face. The effective number of questionnaires was 125 . The effective rate of the questionnaires was $83.3 \%$.

\section{Results}

\section{Socioeconomic Characteristics of the Respondents}

The basic socio-economic information of the respondents is shown in Table 1. Of the 125 respondents, 74 $(54.3 \%)$ were male and $51(45.7 \%)$ female. In terms of nationality structure, there are 59 Hans and 66 Mongolians. The mean age was 56.63 years old, ranging from 18 to 85 years old; 34 were illiterate with no formal education and five respondents had a college education. The average income a family was 51,213 RMB per year. 
Table 1

Socioeconomic Characteristics of the Respondents

\begin{tabular}{|c|c|}
\hline Item & $\mathrm{N}$ \\
\hline \multicolumn{2}{|l|}{ Sex } \\
\hline Male & 74 \\
\hline Female & 51 \\
\hline \multicolumn{2}{|l|}{ Nationality } \\
\hline Han & 59 \\
\hline Mongolian & 66 \\
\hline \multicolumn{2}{|l|}{ Age (yr) } \\
\hline$<20$ & 1 \\
\hline $20-29$ & 3 \\
\hline $30-39$ & 5 \\
\hline $40-49$ & 27 \\
\hline$\geq 50$ & 89 \\
\hline \multicolumn{2}{|l|}{ Education } \\
\hline Illiterate & 34 \\
\hline Elementary & 35 \\
\hline Senior & 40 \\
\hline Higher & 11 \\
\hline Associate degree and above & 5 \\
\hline \multicolumn{2}{|c|}{ Financial characteristics income (x 10,000 RMB) } \\
\hline$<1$ & 13 \\
\hline $1-2$ & 13 \\
\hline $2-3$ & 18 \\
\hline $3-4$ & 10 \\
\hline $4-5$ & 19 \\
\hline $5-6$ & 25 \\
\hline $6-7$ & 14 \\
\hline$>7$ & 13 \\
\hline
\end{tabular}

The Influence of Mining on Respondents

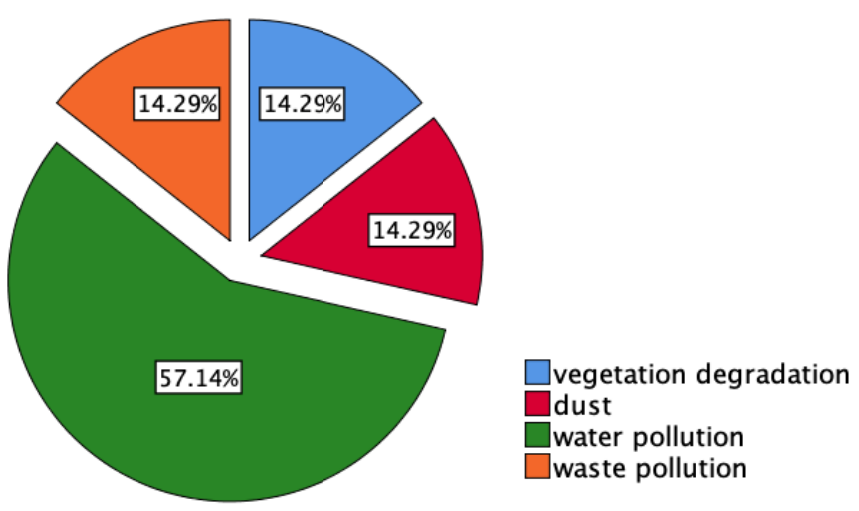

Figure 1. What was the perception of herdsmen who think the main environmental problem caused by mining? 


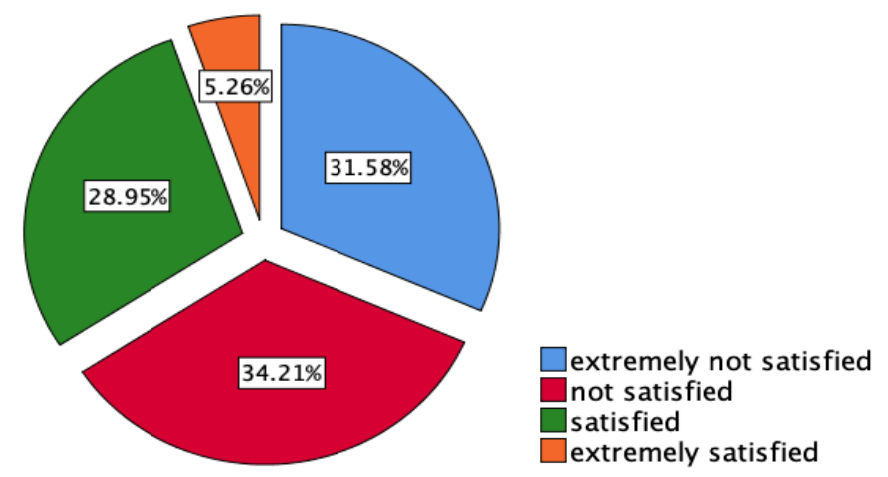

Figure 2. Did the herdsman satisfy with the compensation they received from the mining enterprise?

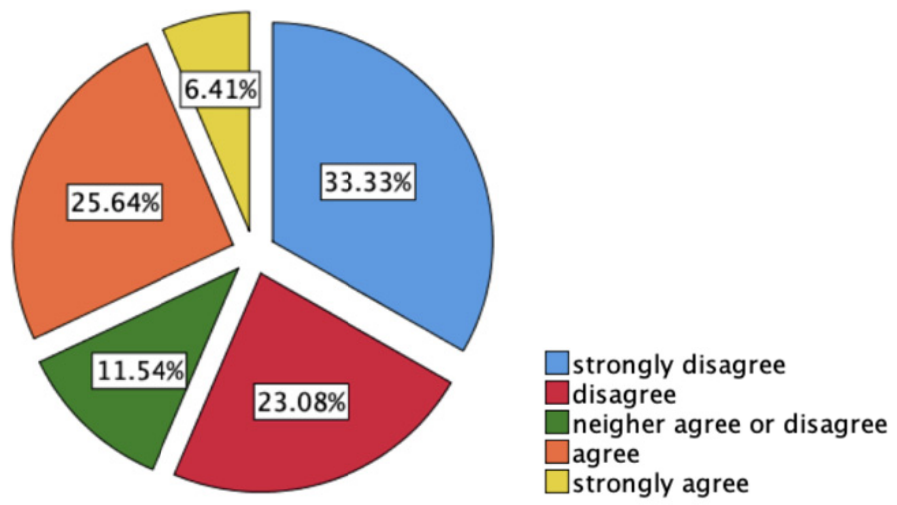

Figure 3. What was the opinion of herdsmen regarding the mining in grasslands?

The pollution of mineral exploitation on grassland is multifaceted. According to Figure 1, the main environmental problem caused by mining included water pollution (57.14\%), dust (14.29\%), vegetation degradation (14.29\%), and waste pollution (14.29\%). Waste-rock piles and tailing repositories are a significant concern at large to medium-scale mining operations. A study indicates that the tailing water by mining directly affects the stream water and indirectly affects groundwater through recharge processes (Battogtokh, Lee, \& Woo, 2014, pp. 3363-3374). Resulting in destruction of the vegetation, exacerbating soil erosion and land desertification, it is also likely making the fragile grassland ecosystem never return to its initial state. This process not only directly causes large areas of grazing grassland to collapse in mined-out areas, but also leads to the degradation of arable land, even causing these lands to become unproductive. Local herds also complained that the contaminated water had affected on both the growth of plants in the surrounding mining area and the availability of drinkable water for people and livestock. Blowing tailing dust is also a serious environmental issue. Dust can be caused by metallic ore crushing operations, drilling operations and trucks being driven on unsealed roads, wind blowing over areas disturbed by mining. Regular dust from mining operations will cover plant foliage that livestock have to consume for their survival and cause eye injury, bronchial complaints, and silicosis. Even local sheep have developed respiratory problems and died after eating poisoned grass. URB is in the transition zone of grassland and desertification areas. The grassland ecological environment system is fragile and sensitive. However, that road construction during the development of the mining areas caused obvious damage to vegetation. The grassland indices of coverage, biomass, and bio-abundance within the radius of $500 \mathrm{~m}$ of the mining areas were much lower in value than those in other areas (Bai, Wu, \& Shen, 2016, pp. 178-186). Herds 
also regarded that the closer to the mining area, the more serious the grassland degradation. Mines produce large amounts of waste because the ore is only a small fraction of the total volume of the mined material (Dudka \& Adriano, 1997, pp. 590-602). A large number of deserted copper mine tailings dump and construction waster covers a large area of grassland. These wastes may contain large quantities of dangerous substances, such as heavy metals, which are an additional potential dander and threat to the fragile grassland ecosystem. Animals can be poisoned directly by mine products and residuals. Bioaccumulation in the plants or the smaller organisms they eat can also lead to poisoning: Horses, goats, and sheep are exposed in certain areas to potentially toxic concentration of copper in grass (Pyatt, Gilmore, Grattan, Hunt, \& McLaren, 2000, pp. 771-778).

Mining compensation assumed enormous importance for the local herdsman. Based on existing compensation standard, they can get three kinds of compensation by mining enterprises. The first part is 4.74 yuan $/ \mathrm{mu} /$ year of grazing prohibition fee. The second part is the $2.53 \mathrm{yuan} / \mathrm{m}^{2}$ of grassland occupation subsidy. However, this standard is limited to herdsmen near copper mines. Moreover, compensation for land use is opaque, weak, and poorly regulated. As a result, the compensation that herds received was worth a small fraction of its value and most herdsmen did not believe that it was reasonable and can make up for the loss of their livelihood. In our survey, $65.79 \%$ of herders stated that they were not satisfied with the amount of compensation they received, while $34.21 \%$ of herdsmen were of the opinion that they satisfied with the compensation (see Figure 2).

Grassland is the material basis for the development of pastoral areas and is the living protection of herdsmen. Although mining in URB has been enhanced the governmental revenues, the herdsmen's livelihood was threatened by mining. Many herds were unhappy about the mining. According to the survey of the opinions of local herds, $56.41 \%$ of herdsmen disagreed mining in grassland. Only $32.05 \%$ of the surveyed herdsmen agreed (see Figure 3).

\section{WTP Analysis}

Table 2

Willingness to Pay

\begin{tabular}{lll}
\hline & Frequency & Percentage \\
\hline WTP $\geq$ Lowest bid $(100)$ & 78 & 62.4 \\
$0<$ WTP $<$ Lowest bid $(100)$ & 17 & 13.6 \\
WTP $=0$ & 30 & 24.0 \\
Total & 125 & 100.0 \\
\hline
\end{tabular}

From Table 2, out of the 125 successfully completed respondents, and 24 percent were invalid responses. We note that out of 76 percent that reported positive WTP, 13.6 percent reported WTP values less than the minimum/lowest presented bid. In terms of payment level, the average WTP per household is 641.18 yuan per year; the result shows that mean WTP for the sampled households is estimated to be 641.18 yuan. The reasons for willingness to pay are as follows: Improving the ecological environment is closely related to personal life; for the good environment of the next generation, it is a response for them to protect the environment. The reasons for the unwillingness to pay are as follows: The destruction of the environment is caused by the mining enterprises and should be borne by the enterprises; the ecological environment belongs to public affairs and should be borne by the government; the respondents had low income and heavy family burden and could not afford to pay.

Based on the principle of random sampling, we can therefore use the result to calculate total willingness to pay for the relevant population in URB. 


$$
N(\overline{w t p}-t \mu \overline{w t p}) \leq N \overline{W T P} \leq N(\overline{w t p}+t \mu \overline{w t p})
$$

In the above formula, $\overline{w t p}$ is the mean WTP for the sampled households; $\overline{W T P}$ is the value for environmental losses in the mining area of URB; $t$ means probability degree; $\mu \overline{w t p}$ is the standard error of mean. With the $95 \%$ confidence interval, $\overline{W T P}$ is estimated to be 641.18 yuan annually with interval estimates of 326.72 yuan and 1,053.71 yuan. We expand the $\overline{W T P}$ estimate for the model without covariates to the population value here. Based on the government figures, there were 24,597 households in mining area of URB in 2017. Multiplying this by the mean WTP and annualizing it yields a total of approximately $15,771,104.5$ yuan with interval estimates of $8,036,331.84$ yuan and $25,918,104.9$ yuan. If the ecological restoration period is 20 years, the whole environmental losses within mineral exploitation in URB will between 160,726,637 yuan and $518,362,098$ yuan.

\section{Conclusions and Implications}

The mineral resources in the grassland of IM have helped to drive China's prosperity. Meanwhile, the grassland is and continues to be an important source of livelihood to the herdsman in terms livestock support, and income generation. However, mining in grassland has exerted a negative influence on herds' livelihood. The eco-compensation fee can only compensate the external costs insufficiently. Herds have a right to expect fair compensation within mining. How to calculate reasonable compensation value is the key to this problem.

The main objective of this study was to obtain estimates of WTP values for the environmental pollution by mining in the pastoral area of URB. The study shows the main environmental problem within mining exploitation included water pollution, dust, vegetation degradation, and waste pollution. At least 76 percent of respondents had willingness to pay for environmental loss. This WTP has been estimated at 641.18 yuan annually. The estimate of WTP to relevant herds in the mining area of URB was 15,771,104.5 yuan annually. Combined with the results of this study, we propose following policy recommendations.

First, the environmental disruption and pollution which is caused by mineral exploitation in grassland is closely related to the ineffective compensation and the lack of environmental right. Thus, the key to solve the problem is to set up the real paid use system of mineral resources and property right system of environment. The state needs to regulate the existing irrational distribution pattern by the tax and other means. Some countermeasures and proposals should be proposed, including building the legal system on interest compensation of the mineral exportation in grassland, determining collecting channels, standards, and methods of the compensation funds, improving impact assessment system of mining environment and establishing a special management department for grassland ecological environment in mining areas, constructing the administrative compensation system on environmental damage of mineral enterprises and the transferring payment system on ecological compensation of mineral grassland.

Second, the current compensation mechanism of mineral exploitation in the pastoral areas should be reformed and should make the livelihood of animal husbandry a priority. According to the results of our study, the existing problems are that there is no intermediary to play a key role in reaching the eco-compensation agreement and the compensation standard does not include the opportunity costs. Especially, the principle of proximity compensation ignores the integrity of the ecology and the vulnerability of animal husbandry and has no long-term consideration for the sustainable livelihood of pastoralists. A three-dimensional compensation mechanism for the mineral exploitation, which mainly consists of livelihood compensation, intergenerational 
compensation, and ecological environment compensation, should be established in the mining area. The governments should develop relevant policies to improve the income of herds within mineral exploitation.

In conclusion, this study demonstrated the applicability of the CVM to the issue of the compensation for herds within mining in grassland. The empirical results from this study suggest some important ideas and may act as a good foundation for many more studies on the ecological and environmental compensation within mineral exploitation in the pastoral area of IM.

\section{References}

Battogtokh, B., Lee, J. M., \& Woo, N. (2014). Contamination of water and soil by the Erdenet copper-Molybdenum mine in Mongolia. Environmental Earth Sciences, 71(8), 3363-3374.

Bai, S. Y., Wu, Q., \& Shen, W. S. (2016). Characteristics of land degradation in mining areas of Inner Mongolia Grassland. Journal of Ecology and Rural Environment, 32(2), 178-186.

Cao, J. J., Holden, N. M., \& Song, Q. X. Y. (2012). Potential use of willingness to accept (WTA) to compensate herders in Maqu County, China, for reduced stocking. Rangeland Ecology \& Management, 65(5), 533-537.

Chapman, J., Ortoleva, P., \& Snowberg, E. (2017). Willingness-to-pay and willingness-to-accept are probably less correlated than you think. New York, NY: Social Science Electronic Publishing.

Carson, R. T., Flores, N. E., \& Meade, N. F. (2001). Contingent valuation: Controversies and evidence. Environmental and Resource Economics, 19, 173-210.

Da, L. T., \& Zheng, Y. S. (2006). Pastoral area and market: Pastoralists economy. Beijing: Social Sciences Academic Press.

Da, L. T., \& Yu, H. X. (2015). A study of the profit distribution in the exploitation of mineral resources-using Inner Mongolia as an example. Journal of Inner Mongolia University, 47(5), 84-93.

Daia, G. S., \& Ulgiatib, S. (2014). The false promises of coal exploitation: How mining affects herdsmen well-being in the grassland ecosystems of Inner Mongolia. Energy Policy, 4, 146-148.

Dudka, S., \& Adriano, D. C. (1997). Environmental impacts of metal ore mining and processing: A review. Journal of Environment Quality, 26(3), 590-602.

Fried, B. M., Adams, R. M., \& Bergland, B. O. (1995). Changes and challenges in the wildlife profession. Willingness to pay for a change in elk hunting quality. Wildlife Society Bulletin, 23(4), 680-686.

Gegengaowa. (2004). Mongolian ecological culture. Hohhot: Inner Mongolia Educational Press.

Horowitz, J. K., \& McConnell, K. E. (2002). A review of WTA/WTP studies. Journal of Environmental Economics and Management, 44(3), 426-447.

Li, G. P. (2014). Research on paid use system and eco-compensation mechanism of mineral resources. Beijing: Economic Sciences Press.

Li, G. P., Guo, J., Li, Z., \& Zeng, X. F. (2011). The difference between the WTP and WTA of the ecological environment improvement in the coal mine area: Take Shenmu County, Fugu County and Yuyang District as example. Statistics \& Information Forum, 26(7), 98-104.

Liu, G. H., Wan, J., Zhang, H. Y., \& Cai, L. J. (2008). Eco-compensation policies and mechanisms in China. Review of European Community \& International Environmental Law, 17, 234-242.

Lu, J. H., Chen, Y., \& Zhu, M. Q. (2018). Study on the tourists' willingness to pay for ecological compensation in Zhalong Nature Reserve. Ecological Economy, (7), 208-214.

Mitchell, R. C., \& Carson, R. T. (1993). Using surveys to value public goods: The contingent valuation method. Baltimore, Maryland: Hopkins University Press.

Pyatt, F. B., Gilmore, G., Grattan, J. P., Hunt, C. O., \& McLaren, S. (2000). An imperial legacy? An exploration of the environmental impact of ancient metal mining and smelting in Southern Jordan. Journal of Archaeological Science, 27(9), 771-778.

Qu, X. E., \& Li, G. P. (2012). The environmental value loss assessment of coal resources development in the Northern Shaanxi. Journal of Arid Land Resources and Environment, (4), 73-78.

Ready, R. C., Buzby, J. C., \& Hu, D. (1996). Differences between continuous and discrete contingent value estimate. Land Economics, 72(3), 397-411.

Ready, R. C., Navrud, S., \& Dubourg, W. R. (2001). How do respondents with uncertain willingness to pay answer contingent valuation questions. Land Economics, 77(3), 315-326. 
Shiell, A., \& McIntosh, K. (2008). Subject variation more than values clarification explains the reliability of willingness to pay estimates. Health Econ, 17, 287-292.

Urat Rear Banner Local Chronicles Compilation Committee. (2005). Urat Rear Banner local chronicles. Hohhot: Yuan Fang Press.

Wang, W. C. (2010). Research on the harmonious construction of the relationship between the resources development of the west and the national interest. Beijing: Minzu University of China Press.

Zhang, Q. (2016a). Analysis of the effect of industrial and mining development in pastoral area on livelihoods of herdsmen-Based on investigation on B gachaa of Inner Mongolia. Chinese Rural Economy, 7, 59-66.

Zhang, Q. (2016b). The logic of interest distribution and herdsmen's profit within mineral exploitation: A case study of Huogeqi Sum in Inner Mongolia. Sociology and Anthropology, 4(9), 836-843.

Zhu, H. G., \& Kang, L. Y. (2016). Analysis on farmers' willingness of accepting compensation and its influencing factors in returning farmland to wetland based on WTA-An empirical study in Poyang Lake Region. Agricultural Economics and Management, 3, 60-67. 